\title{
SISTEM KONTROL PERTERNAKAN IKAN DENGAN MENGGUNAKAN MIKROKONTROLLER BERBASIS ANDROID
}

\author{
Anip Febtriko \\ Teknik Informatika, Fakultas Teknik, Universitas Abdurrab \\ Jl. Riau Ujung No. 73 Pekanbaru Riau Indonesia \\ E-Mail : aniep.febtric@gmail.com
}

\begin{abstract}
ABSTRAK
Mikrokontroler perangkat elektronik digital yang memiliki input dan output serta kontrol dengan program yang bisa ditulis dan terhapus dengan cara yang khusus, bagaimana mikrokontroler sebenarnya membaca dan menulis data. Mikrokonktroler digunakan dalam produk dan peralatan dikendalikan secara otomatis, seperti sistem kontrol mesin, remote kontrol, mesin kantor, peralatan rumah tangga, alat berat, dan mainan. Mikrokontroler dapat sebagai sistem kontrol di peternakan ikan dalam pengendalian pasokan air dan mengontrol makan tersebut. alat penghubung dengan aplikasi Android dengan bluetooth. Kemudahan dalam mengendalikan peternakan ikan android didukung, which android akan diberikan aplikasi ditempatkan di dalam android. Dalam antarmuka aplikasi android Menyediakan fasilitas untuk mengontrol Pisciculture.
\end{abstract}

Kata kunci : Mikrokontroler, Android, Bluetooth

\begin{abstract}
Microcontroller a digital electronic device that has inputs and outputs as well as control with a program that can be written and erased in a special way, how the actual microcontroller to read and write data. Microcontroller used in products and equipment are controlled automatically, such as engine control systems, remote controls, office machines, household appliances, heavy equipment, and toys. Microcontroller can be as control systems in fish farms in the control of water supply and control the feeding. Liaison tool with Android apps with bluetooth. The ease in controlling fish farms supported android, android which will be given application is placed inside the android. In the android application interface provides the facility to control pisciculture.
\end{abstract}

Key words : Microcontroller, Android, Bluetooth

\section{PENDAHULUAN}

Mikrokontroler

perkembangan dari sebuah teknologi mikroprosesor, mikrokontroler dengan kemampuanya yang dapat diprogram ulang (eraseable and programmable) diharapkan dapat memenuhi kebutuhan pasar dalam menghasilkan teknologi baru. Mikrokontroler hadir untuk memenuhi selera industri dan para konsumen akan kebutuhan pemakaian alat-alat bantu yang lebih baik dan canggih atau bahkan dalam menciptakan mainan berteknologi tinggi.

Dalam peneletian ini akan menerapkan sistem kontrol peternakan ikan dengan menggunakan mikrokontroller berbasiskan Arduino. Dengan adanya alat ini memudahkan peternak ikan dalam pertenakan dengan alat yang digunakan.

\section{Rumusan Masalah}

Berdasarkan latar belakang yang dijelaskan diatas, permasalahan yang timbul yaitu bagaimana merancang dan membuat Sistem kontrol peternakan ikan dengan menggunakan mikrokontroller berbasis Android?. 


\section{Batasan Masalah}

Berdasarkan perumusan masalah diatas, maka penelitian ini dibatasi pada hal-hal berikut ini:

1. Sistem kontrol pemberian makanan ikan.

2. Sistem kontrol air peternakan ikan

\section{Tujuan}

Adapun tujuan penelitian yang akan dicapai dalam penulisan ini adalah sebagai berikut :

1. Sebagai bahan ajar

2. Pemakalah dalam temu ilmiah

\section{Manfaat}

1. Agar dapat digunakan sebagai alat kontrol dalam pemberian pakan ikan.

2. Agar bisa digunakan dalam mengkontrol air.

\section{Mikrokontroler}

Mikrokontroler adalah sebuah sistem komputer yang seluruh atau sebagian besar elemennya dikemas dalam satu chip IC, sehingga sering disebut single chip microcomputer. Mikrokontroler merupakan sistem komputer yang mempunyai satu atau beberapa tugas yang sangat spesifik (chamim, 2010).

Elemen mikrokontroler tersebut diantara nya :

1. Pemroses (processor)

2. Memori

3. Input dan output.

Mikrokontroler merupakan komputer didalam chip yang digunakan untuk mengontrol peralatan elektronik, yang menekankan efisiensi dan efektifitas biaya. Secara harfiahnya mikrokontroler bisa disebut "pengendali kecil" dimana sebuah sistem elektronik yang sebelumnya banyak memerlukan komponen-komponen pendukung seperti IC TTL dan CMOS dapat direduksi atau diperkecil dan akhirnya terpusat serta dikendalikan oleh mikrokontroler ini.

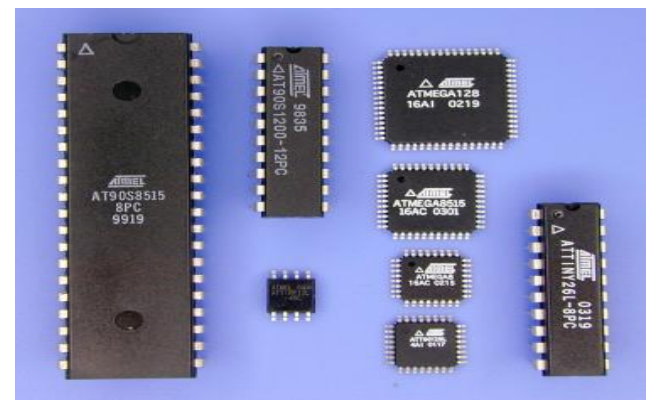

Gambar 1. Bentuk dan Jenis

Mikrokontroler

\section{Arduino Uno}

Uno Arduino adalah board berbasis mikrokontroler pada ATmega328 . Board ini memiliki 14 digital input / output pin (dimana 6 pin dapat digunakan sebagai output PWM), 6 input analog, $16 \mathrm{MHz}$ osilator kristal, koneksi USB, jack listrik tombol reset. Pin-pin ini berisi semua yang diperlukan untuk mendukung mikrokontroler, hanya terhubung ke komputer dengan kabel USB atau sumber tegangan bisa didapat dari adaptor AC-DC atau baterai untuk menggunakannya(Kadir, 2012).

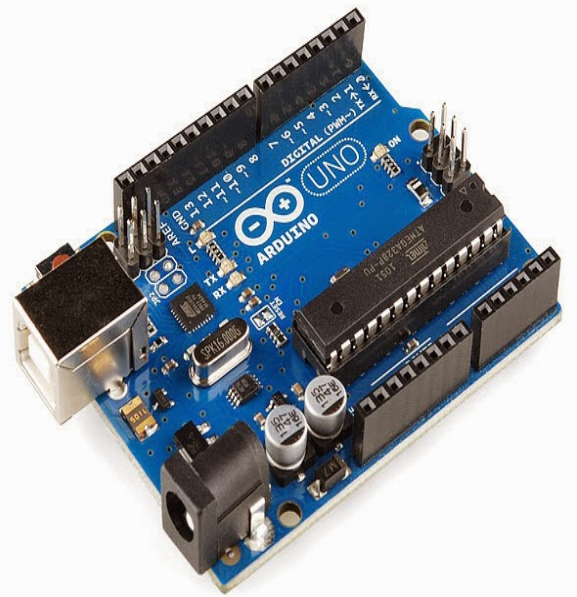

Gambar 2. Arduino Uno 


\begin{tabular}{cl}
\hline \multicolumn{2}{c}{ Tabel 1. Deskripsi Arduino Uno } \\
\hline Mikrokontroller & \multicolumn{1}{c}{ Atmega328 } \\
\hline Operasi Voltage & $5 \mathrm{~V}$ \\
\hline Input Voltage & $7-12 \mathrm{~V}$ \\
& (Rekomendasi) \\
\hline Input Voltage & $6-20 \mathrm{~V}$ (limits) \\
\hline I/O & 14 pin (6 pin \\
& untuk PWM) \\
\hline Arus & $50 \mathrm{~mA}$ \\
\hline Flash Memory & $32 \mathrm{~KB}$ \\
\hline Bootloader & SRAM 2 KB \\
\hline
\end{tabular}

\section{Input dan Output}

Masing-masing dari 14 pin digital pada Uno dapat digunakan sebagai input atau output, menggunakan fungsi pinMode, digitalWrite dan digitalRead, Mereka beroperasi di 5 volt. Setiap pin dapat memberikan atau menerima maksimum 40 $\mathrm{mA}$ dan memiliki resistor pull-up internal dari $20-50 \mathrm{~K} \Omega$. Selain itu, beberapa pin memiliki fungsi khusus:

1. Serial: 0 (RX) dan 1 (TX). Digunakan untuk menerima (RX) dan mengirimkan (TX) data TTL serial. Pin ini terhubung ke pin yang sesuai dari chip ATmega8U2 USB-to-Serial TTL.

2. Eksternal Interupsi: 2 dan 3. Pin ini dapat dikonfigurasi untuk memicu interupsi pada nilai yang rendah, tepi naik atau jatuh, atau perubahan nilai. Lihat attachInterrupt () fungsi untuk rincian.

3. PWM: 3, 5, 6, 9, 10, dan 11. Menyediakan 8-bit output PWM dengan analogWrite () fungsi.

4. SPI: 10 (SS), 11 (mosi), 12 (MISO), 13 (SCK). Pin ini mendukung komunikasi SPI menggunakan perpustakaan SPI.

5. LED: 13. Ada built-in LED terhubung ke pin digital 13. Ketika pin adalah

nilai TINGGI, LED menyala, ketika pin adalah RENDAH, itu off.

Uno memiliki 6 input analog, diberi label A0 melalui A5, masing-masing menyediakan 10 bit resolusi yaitu 1024 nilai yang berbeda. Secara default sistem mengukur dari tanah sampai 5 volt :

1. TWI: A4 atau SDA pin dan A5 atau SCL pin. Mendukung komunikasi TWI

2. Aref. Referensi tegangan untuk inputanalog. Digunakan dengan analogReference () dan Reset.

\section{Komunikasi}

Uno Arduino memiliki sejumlah fasilitas untuk berkomunikasi dengan komputer, Arduino lain, atau mikrokontroler lain. ATmega328 ini menyediakan UART TTL (5V) komunikasi serial, yang tersedia pada pin digital 0 (RX) dan 1 (TX). RX dan TX LED di board akan berkedip ketika data sedang dikirim melalui chip USB-to-serial dan koneksi USB ke komputer. ATmega328 ini juga mendukung komunikasi I2C (TWI) dan SPI. Fungsi ini digunakan untuk melakukan komunikasi interface pada sistem.

\section{Perangkat lunak (Arduino IDE)}

Lingkungan open-source Arduino memudahkan untuk menulis kode dan meng-upload ke board Arduino. Ini berjalan pada Windows, Mac OS X, dan Linux. Berdasarkan Pengolahan, avr-gcc, dan perangkat lunak sumber terbuka lainnya (Hendriono, 2014). 


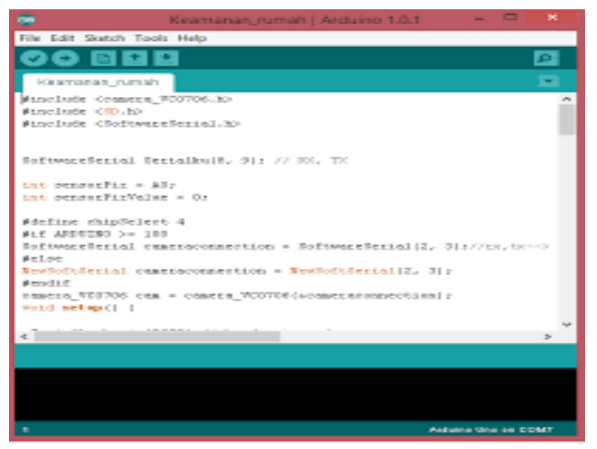

Gambar 3. Tampilan Framework Arduino Uno

\section{Catu daya}

catu daya atau sering disebut juga dengan power supply adalah sebuah piranti yang berguna sebagai sumber listrik untuk piranti lain. Pada dasarnya catu daya bukanlah sebuah alat yang menghasilkan energi listrik saja, namun ada beberapa catu daya yang menghasilkan energi mekanik, dan energi yang lain (Rahmattullah, 2015).

\subsubsection{Resistor}

Resistor merupakan sebuah komponen elektronika yang termasuk komponen pasif yang mempunyai sifat menghambat arus listrik. Dalam sebuah rangkaian elektronika, resistor bisa difungsikan sebagai berikut (Putra, 2006):

1. Sebagai pembagi arus

2. Sebagai penurun tegangan

3. Sebagai pembagi tegangan

4. Sebagai penghambat aliran arus listrik

Satuan nilai dari resistor adalah ohm, biasa disimbolkan $\Omega$. Besarnya nilai hambatan pada resistor biasanya disebut dengan resistansi.

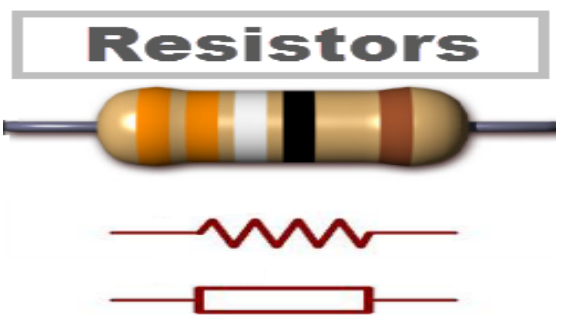

Gambar 4. Resistor

\section{Capasitor}

Capasitor adalah komponen elektronika yang mampu menyimpan arus dan tegangan listrik untuk sementara waktu. Seperti juga halnya resistor, kapasitor termasuk salah satu komponen pasif yang banyak digunakan dalam membuat rangkaian. Kapasitor mempunyai nilai satuan, yang dinyatakan dengan FARAD (F). Untuk satuan farad tersebut dalam bentuk pecahan (Putra, 2006) :

- 1 farad $(F)=1000000$ uf (mikro farad)

- 1 mikro farad $(F)=1000$ uf (nano farad)

- 1 nano farad $(F)=1000$ uf (piko farad)

Adapun fungsi dari kapasitor yaitu:

1. Sebagai penghubung (coupling) yang menghubungkan masingmasing bagian dalam suatu rangkaian.

2. Memisahkan arus bolak balik dari arus searah

3. Sebagai filter yang dipakai pada rangkaian rangkaian catu daya

\section{Metode Waterfall}

Waterfall atau sering juga disebut air terjun adalah sebuah metode dalam pengembangan sistem yang menyediakan pendekatan alur hidup perangkat lunak secara terurut yang dimulai dari analisis, desain, pengodean dan pengujian (Rosa, 2014). Dan untuk gambarannya dapat di ilustrasikan seperti gambar berikut ini :

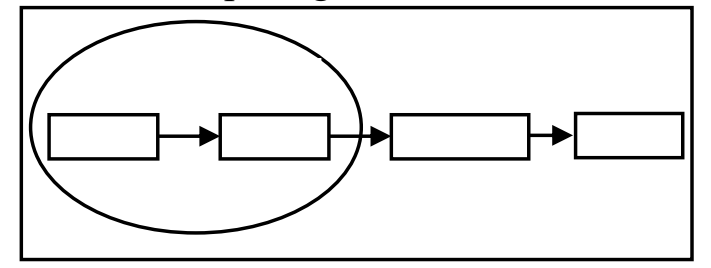


Gambar 5. Ilustrasi Model Waterfall

Inti dari metode waterfall adalah pengerjaan dari suatu sistem dilakukan secara berurutan atau secara linear. Jadi jika langkah satu belum dikerjakan maka tidak akan bisa melakukan pengerjaan langkah 2, 3 dan seterusnya. Secara otomatis tahapan ke-3 akan bisa dilakukan jika tahap ke-1 dan ke-2 sudah dilakukan.

\section{Keunggulan dan Kelemahan Metode Waterfall}

Keunggulan waterfall dalam membangun dan mengembangkan suatu sistem (Agus, 2013). Antara lain:

1. Kualitas dari sistem yang dihasilkan akan baik. Ini dikarenakan oleh pelaksanaannya secara bertahap. Sehingga tidak terfokus pada tahapan tertentu.

2. Dokumen pengembangan sistem sangat terorganisir, karena setiap fase harus terselesaikan dengan lengkap sebelum melangkah ke fase berikutnya. Jadi setiap fase atau tahapan akan mempunyai dokumen tertentu.

Kelemahan waterfall dalam membangun dan mengembangkan suatu sistem,antara lain:

1. Diperlukan majemen yang baik, karena proses pengembangan tidak dapat dilakukan secara berulang sebelum terjadinya suatu produk.

2. Kesalahan kecil akan menjadi masalah besar jika tidak diketahui sejak awal pengembangan.

3. Pelanggan sulit menyatakan kebutuhan secara eksplisit sehingga tidak dapat mengakomodasi ketidakpastian pada saat awal pengembangan.

\section{METODE}

Kerangka Penelitian

Dalam pembuatan penelitian ini dalam perancangan sistemnya peneliti menggunakan metode waterfall, yang dimana pelaksanaannya dilakukan tahap demi tahap secara berurutan sehingga kualitas dari sistem akan lebih baik.

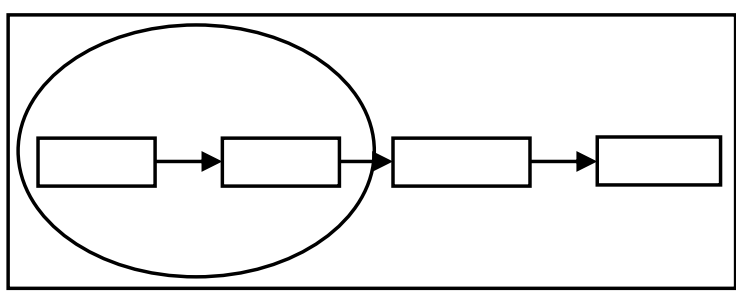

Gambar 6. Tahapan Metode Waterfall

\section{Analisis}

Dalam tahapan analisis ini adalah melakukan analisa terhadap kebutuhan perangkat keras (hardware) dan perangkat lunak (software) untuk mencari spesifikasi secara rinci sistem yang akan di buat, dengan mengumpulkan data dari beberapa literatur yang berasal dari buku, website dan jurnal-jurnal penelitian terdahulu. Penelitian yang akan dibuat adalah sebuah alat yang dapat mengontrol pemeliharaan ternak ikan. Berikut adalah spesifikasi kebutuhan untuk membuat alat sistem kontrol pemeliharaan ternak ikan.

Tabel 2. Alat dan Bahan

\begin{tabular}{ccc}
\hline Hardware & \multicolumn{2}{c}{ Software } \\
\hline Arduino Uno & OS & \\
LED & Windows & 10 \\
Kapasitor & 64 Bit & \\
elektrolit (Elko) & Arduino & \\
PCB & IDE 1.0 .1 \\
(Printed Circuit & & \\
Board) & \\
\hline
\end{tabular}

\section{Desain}


Pada tahap desain, peneliti membuat alur kerja sistem yang telah didapat dari analisis pengumpulan kebutuhan. Kemudian pengumpulan peralatan dan bahan-bahan untuk membuat perangkat.

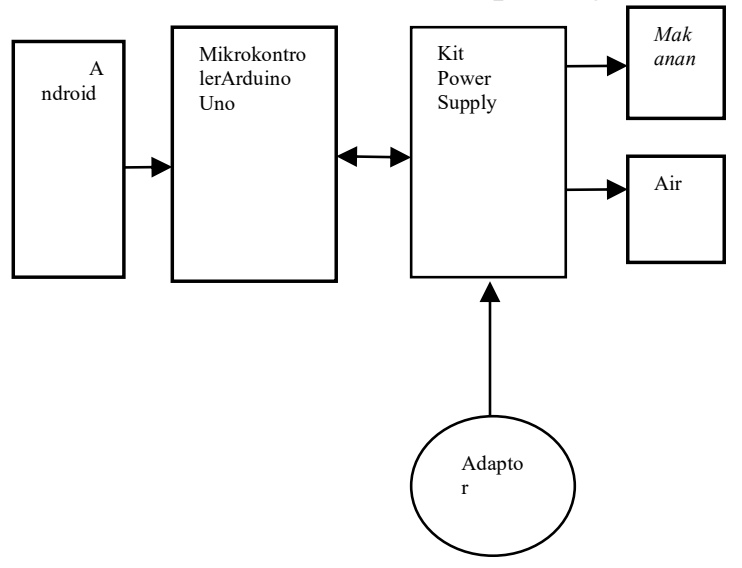

Gambar 7. Diagram Blok Rangkain

\section{Pengkodean}

Setelah melakukan perancangan perangkat lunak yang dibuat pada tahap desain maka pada tahap pengkodean ini dilakukan membuat sketch untuk menjalankan pemproses arduino uno atau perintah yang dibutuhkan.

\section{Pengujian}

Pada tahap ini dilakukan uji coba program untuk memastikan program bebas dari kesalahan-kesalahan, setelah itu alat dicoba dan dites proses kerja nya. Pengujian ini meliputi beberapa tahap, yaitu:

1. Pengujian perangkat keras (Hardware). Pengujian hardware bertujuan untuk memastikan tidak ada kesalahan dalam rangkaian elektronik.

2. Pengujian perangkat lunak (Software). Pengujian ini dilakukan dengan melakukan pengujian terhadap program dengan cara memberi masukan dan mengamati keluarannya. Pengujian ini meliputi pengujian program yang telah dimasukkan ke dalam Arduino.

3. Pengujian Keseluruhan.

Setelah perangkat keras (hardware) dan perangakat lunak (software) dikombinasikan menjadi sebuah sistem, kemudian dilakukan pengujian keseluruhan sistem yang bertujuan untuk mengetahui apakah sistem berjalan dengan baik atau tidak.

\section{HASIL}

\section{Perancangan Sistem}

Analisa perancangan sistem kontrol yang akan dibangun meliputi:

1. Merancang rangkaian arduino uno, module bluetooth dan relay

2. Merancang aplikasi di android untuk mengendalikan alat

3. Proses pengkoneksian arduino dengan smartphone android menggunakan module bluetooth.

4. Menerapkan output pada channel relay untuk menjalankan kontrol kerja alat.

\section{Blok Diagram Dan Cara Kerja}

Untuk lebih memudahkan proses perancangan dan cara kerja masing-masing rangkaian maka akan dibuat suatu diagram blok terlebih dahulu. Hal ini sangat penting, karena dalam pembuatan suatu alat setiap rangkaian saling berhubungan dan mempengaruhi kinerja alat lainnya. Sehingga hasil yang didapat sesuai dengan keinginan dan teori yang berlaku. 


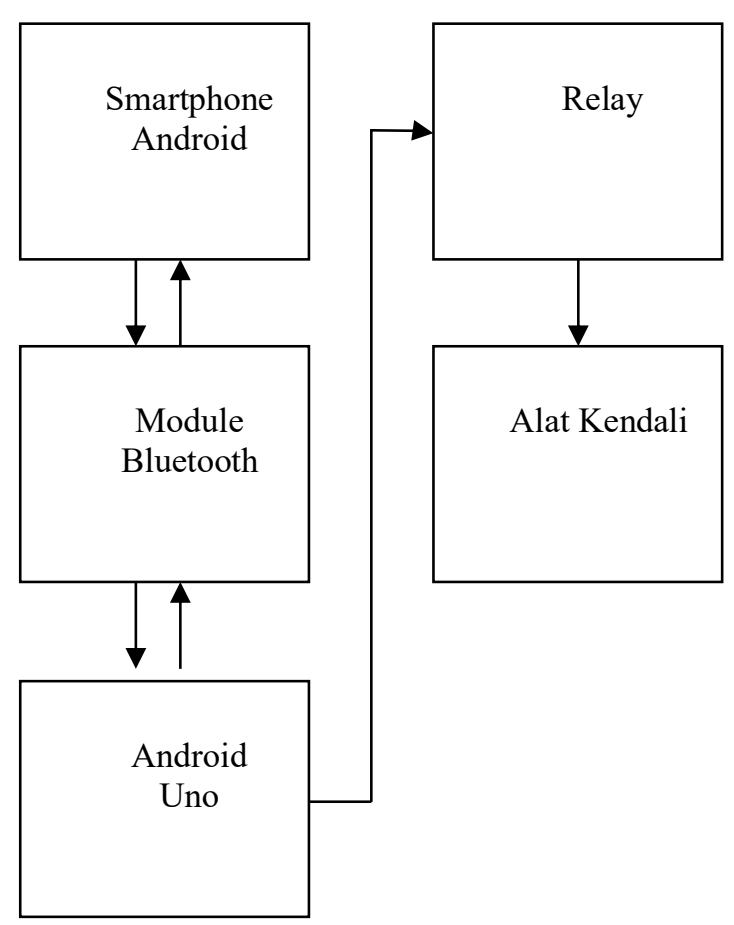

Gambar 8. Blok Diagram Dan Cara Kerja

\section{Flawchart}

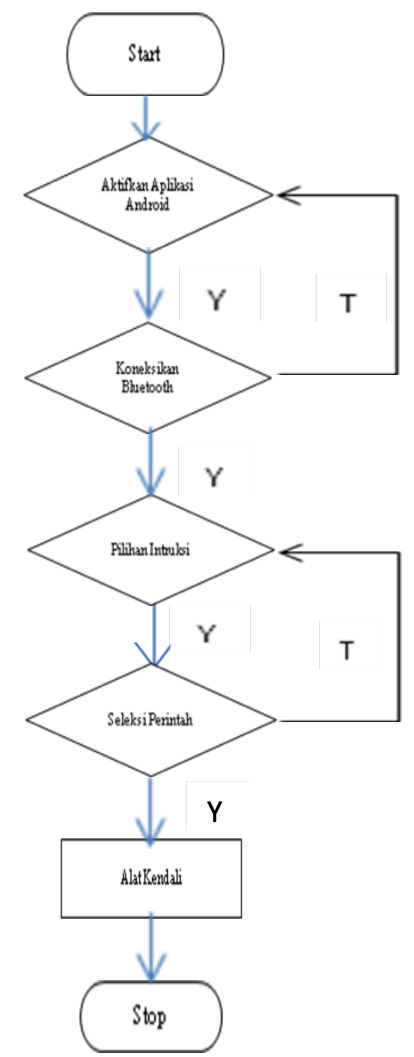

Gambar 9. Flowchart
Keterangan Flowchart :

a. Awal mulai aktifkan aplikasi android

b. Kemudian lakukan pengkoneksian bluetooth, jika tidak aktifkan ulang aplikasi android

c. Apabila bluetooth sudah terkoneksi lakukan perintah dengan menekan tombol di aplikasi

d. Sistem akan mengecek perintah, jika kata tidak benar kembali melakukan perintah, jika benar Relay akan $O N$ dan Alat Kontrol $O N$

e. Lalu lakukan lagi perintah,

f. Sistem akan mengecek perintah, jika tidak benar kembali melakukan perintah, jika benar Relay akan $O F F$ dan Alat kontrol $O F F$

g. Matikan aplikasi, jika tidak lakukan perintah.

\section{Analisa Perangkat Keras}

Untuk memulai perancangan, melakukan analisa dengan menggambarkan skema dari rangkaian perangkat keras agar bisa bekerja secara efektif.

1. Skema Arduino

Arduino UNO adalah sebuah board mikrokontroler yang didasarkan pada Atmega328 (datasheet). Arduino UNO mempunyai 14 pin digital input/output, 6 input analog

2. Skema Rangkaian Arduino dan Bluetooth

Didalam perancangannya alat ini menggunakan modul Bluetooth yang berfungsi sebagai media koneksi antara Arduino Uno dengan Smartphone. Adapun gambar 
rangkaian skema tersebut seperti gambar dibawah ini:

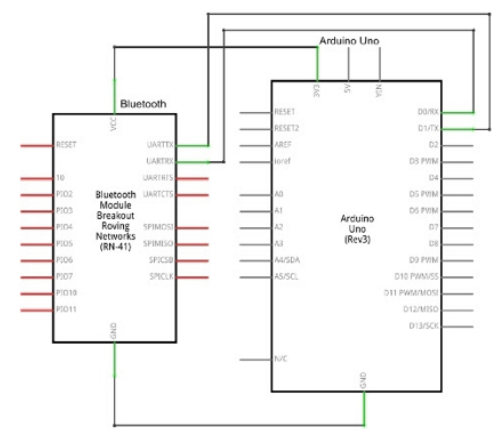

Gambar 12. Skema Rangkaian Module

Bluetooth dengan Arduino

Dalam rancangan ini module bluetooth memiliki kemampuan berkomunikasi secara serial dengan protokol standar Bluetooth versi 2.0. Papan inti menggunakan chipset CSR BC417 dan sudah dipasangkan dengan adapter koneksi sehingga mudah untuk digunakan, cukup menghubungkan modul ini dengan kabel koneksi.

3. Skema Rangkaian Relay dengan Arduino

Dalam perancangan ini menggunakan Relay 4 Channel yang berfungsi untuk memutuskan dan mengalirkan arus listrik ke dalam elektronik. Adapun gambar rangkaian skema tersebut sebagai berikut :

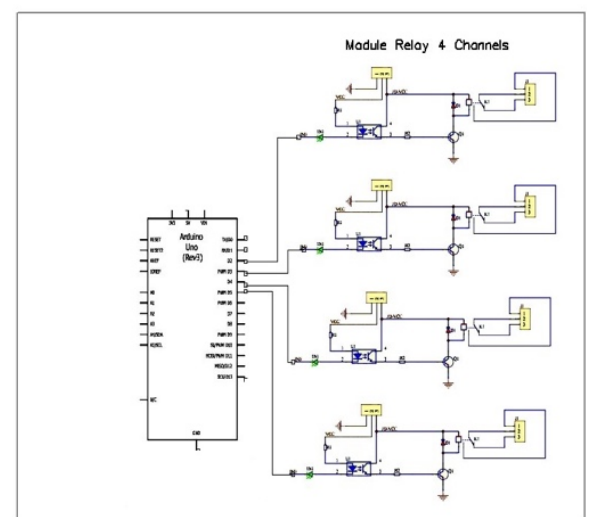

Gambar 11. Skema Rangkaian Relay dengan Arduino
Relay yang dipakai untuk rancangan ini memakai Relay 4 channel yang tiaptiap channel bisa berfungsi untuk memutuskan dan mengalirkan arus listrik. Kontak poin relay terdiri dari 2 jenis yaitu : Normally Close (NC) dan Normally Open (NO).

\section{Perancangan dan Pengujian Rangkaian Perangkat Keras (Hardware)}

Pada tahap ini adalah proses perancangan perangkat keras serta melakukan pengujian alat. Pengujian alat dilakukan untuk mengetahui apakah fungsifungsi yang telah direncanakan bekerja dengan baik atau tidak. Pengujian alat juga berguna untuk mengetahui tingkat kinerja dari fungsi tersebut. Setelah dilakukan pengujian, maka dilakukan analisa terhadap apa yang diuji untuk mengetahui keberhasilan dari alat yang dibuat dalam tugas akhir ini.

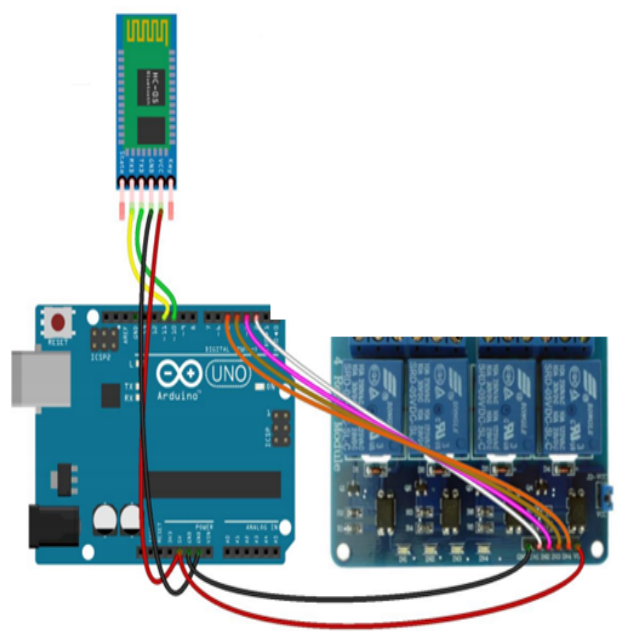

Gambar 13. Rancangan Alat Keseluruhan

Pembuatan alat ini menggunakan 3 elemen yang mendukung sistem kontrol alat elektronik yaitu: Arduino uno, Module Bluetooth, dan Relay. Serta alat elektronik yang akan di kendalikan. Mikrokontroler 
yang dipilih adalah arduino uno karena memiliki clock yang tinggi sebesar $16 \mathrm{MH}$ kapasitas SRAM sebesar 2 Kbyte, 14 buah port I/O, 6 pin input analog dan 6 pin output analog. Kemudian mempunyai 2 buah Pin TX, RX. Karena dalam hal ini pada sistem ini dibutuhkan 2 buah TX, RX untuk pengkoneksian Bluetooth.

Berikut adalah tabel rincian penggunaan pin pada arduino dalam proyek pembuatan alat ini :

Tabel 3. Penggunaan Pin Arduino

\begin{tabular}{|c|c|}
\hline $\begin{array}{l}\text { Arduino } \\
\text { Pin }\end{array}$ & Keterangan \\
\hline 2 & $\begin{array}{l}\text { Pin } 2 \text { pada Arduino untuk } \\
\text { IN } \\
1 \text { pada Relay (input } 1 \text { ) }\end{array}$ \\
\hline 3 & $\begin{array}{l}\text { Pin } 3 \text { pada Arduino untuk } \\
\text { IN } \\
2 \text { pada Relay (input } 2 \text { ) }\end{array}$ \\
\hline 4 & $\begin{array}{l}\text { Pin } 4 \text { pada Arduino untuk } \\
\text { IN } \\
3 \text { pada Relay (input } 3 \text { ) }\end{array}$ \\
\hline 5 & $\begin{array}{l}\text { Pin } 5 \text { pada Arduino untuk } \\
\text { IN } \\
4 \text { pada relay (input } 3 \text { ) }\end{array}$ \\
\hline 10 & $\begin{array}{l}\text { Pin } 10 \text { pada Arduino untuk } \\
\text { RX pada Module Bluetooth }\end{array}$ \\
\hline 11 & $\begin{array}{l}\text { Pin } 11 \text { pada Arduino untuk } \\
\text { TX pada Module Bluetooth }\end{array}$ \\
\hline GND & $\begin{array}{l}\text { Berfungsi sebagai jalur } \\
\text { ground arduino dan } \\
\text { komponen lain }\end{array}$ \\
\hline $5 \mathrm{~V}$ & $\begin{array}{l}\text { Berfungsi sebagai power } \\
\text { untuk Relay }\end{array}$ \\
\hline $3.3 \mathrm{~V}$ & $\begin{array}{l}\text { Berfungsi sebagai power } \\
\text { untuk Module Bluetooth }\end{array}$ \\
\hline
\end{tabular}

untuk memastikan apakah arduino uno dapat berjalan dengan baik dan dapat digunakan pada proyek tugas akhir ini. Driver arduino telah terinstal sebelum nya pada sistem operasi yang digunakan. Papan arduino terkoneksi ke usb port yang ada pada komputer dengan menggunakan kabel usb.

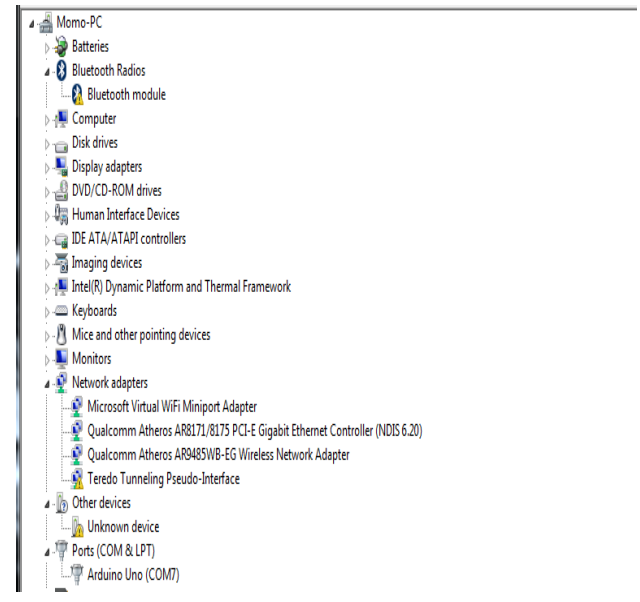

Gambar 14. Koneksi Port Arduino

Pada gambar 4.7 terlihat bahwa arduino terkoneksi pada port COM 7, ini menandakan bahwa arduino telah di supply daya dari komputer dan arduino telah aktif dengan lampu PWR yang berwarna hijau pada papan arduino menyala serta dapat melakukan proses upload kode program pada papan arduino.

\section{Pengujian Rangkaian Module Bluetooth dengan Android}

Pengujian module bluetooth bertujuan untuk mengetahui apakah module bluetooth berfungsi dan bisa digunakan untuk pengkoneksian pada android sebagai jalur penghubung dalam pengiriman data ke arduino.

\section{Pengujian Arduino Uno}

Proses ini adalah pengujian pada mikrokontroler arduino uno yang bertujuan 
Tabel 5. Rangkaian Module Bluetooth pada Arduino

\begin{tabular}{ll}
\hline Module Bluetooth & Arduino Pin Control \\
\hline VCC & $3.3 \mathrm{~V}$ \\
\hline GND & GND \\
\hline TX & Pin 10 \\
\hline RX & Pin 11 \\
\hline
\end{tabular}

Pada tabel 3.2 dapat dilihat bahwa module bluetooth dihubungkan ke power supply melalui pin 3.3V dan pin GND dan untuk pengiriman dan penerimaan data pada pin 10 dan pin 11 pada arduino. Ketika rangkaian sudah terhubung di tandai dengan hidup dan berkedip nya lampu LED warna merah pada module Bluetooth

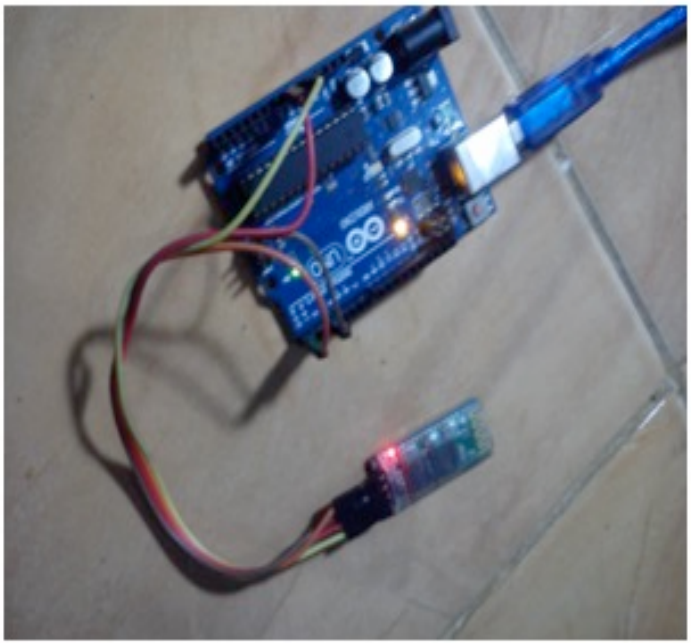

Gambar 15. Rangkaian Arduino dengan Module Bluetooth

Untuk mengetahui jarak yang dapat dijangkau bluetooth dilakukan pengujian diluar rumah agar mengetahui hasil dari jarak bluetooth tampa adanya hambatan atau halangan.
Tabel 6. Jangkauan Koneksi Bluetooth

\begin{tabular}{cl}
\hline Jarak $(\mathrm{M})$ & Hasil \\
\hline 3 & Terdeteksi \\
\hline 5 & Terdeteksi \\
\hline 8 & Terdeteksi \\
\hline 12 & Terdeteksi \\
\hline 15 & Terdeteksi \\
\hline 18 & Terdeteksi \\
\hline 21 & Terdeteksi \\
\hline 25 & Terdeteksi \\
\hline 30 & Terdeteksi \\
\hline 31 & Tidak Terdeteksi \\
\hline
\end{tabular}

Hasil pengujian module bluetooth ini memperlihatkan bahwa koneksi module bluetooth mampu dan terdeteksi hingga jarak 30 meter. Akan tetapi hasil pengujian koneksi bluetooth pada suatu ruangan dan di kontrol dari luar ruangan hanya mampu terdekteksi pada jarak 24 meter saja.

\section{KESIMPULAN}

Sistem kontrol Peternakan Ikan ini dapat disimpulkan sebagai berikut :

1. Sistem ini bekerja dengan baik menggunakan pengendali mikrokontroler arduino dalam pengoperasian data yang dikirim melalui module bluetooth.

2. Jangkauan jarak dari module bluetooth ini adalah 30 meter jika tampa adanya halangan atau hambatan. Jika didalam ruangan atau ada hambatan koneksi module bluetooth hanya terjangkau 24 meter saja.

3. Sistem ini dapat bekerja untuk mengontrol suplai air dan pemberian makan ikan di peternakan ikan. 


\section{DAFTAR PUSTAKA}

[1].Andrianto, H. 2010. Buku Panduan Pelatihan Mikrokontroller AVR Atmega16. 7-15.

[2].Djuandi, Feri. 2011. Pengenalan Arduino. www.tokobuku.com.

[3]. Kadir, Abdul. 2015. From Zero to A Pro. Yogyakarta: ANDI.

[4].Ladjamudin, Al-Bahra. 2005. Analisis dan Desain Sistem Informasi. Graha Ilmu.

[5].Oktofani, Yusuf. 2016. Sistem Pengendalian Suhu Dan Kelembaban Berbasis Wireless Embedded System. Universitas Brawijaya, Malang.

[6].Rodzevski, Alexander. 2009. Wireless Sensor Network With Bluetooth. University of Malmo, Sweden.

[7]. Setiawan, Angga. 2013. Metodologi Pengembangan waterfall. 